\title{
Evaluating the Effects of Climate Change on the Potential Site Productivity of Sugi (Cryptomeria japonica) Planted Forests in Kyushu Island, Japan
}

\author{
Yasushi Mitsuda*1
}

\begin{abstract}
This study aimed to evaluate the effect of climate change on the potential site productivity of sugi (Cryptomeria japonica)-planted forests in Kyushu Island. In this study, potential site productivity was defined as the simulated 10-year average of net primary production by using the carbon balance-based stand growth model. The spatial unit was a 1-km grid, which had the same as resolution as the climate data, and 15-year-old sugi-planted forests were virtually established in each 1-km grid in the Kyushu Island. Maps of site productivity estimated using current and future climatic data were obtained and compared to generate a map of sugi site productivity change. The average difference between the estimated current and future potential site productivity was -2.61 , and the potential site productivity in $87 \%$ of the land area of Kyushu Island and of sugi-planted forests was estimated to decrease with future climatic changes. The increase of respiration rate with an increase in temperature was the main factor for the decrease in the potential site productivity of sugi-planted forests.
\end{abstract}

Keyword: carbon balance-based stand growth model, climate change adaptation option, NPP, potential site productivity, sugi

\section{INTRODUCTION}

Determining a strategy for forest management that can adapt to the predicted future climate change is an urgent issue (IPCC, 2007). Forests have been expected as an important carbon sink and climate change mitigation options in forestry have been studied (e.g. Canadell and Raupach, 2008; Lempriere et al., 2013; Matsumoto et al., 2016). Climate change adaptation options in forestry have been also investigated for conserving forest ecosystems, developing sustainable forest management, and maintaining forest carbon absorption (e.g. Smit et al., 2014; Spies et al., 2010; Spittlehouse and Stewart, 2004). Considering the function of forests as a carbon sink, adaptation options might contribute to the maintenance of carbon absorption rate for future forests under changed climatic conditions. Linking climate change adaptation and mitigation options is required for future sustainable forest management (IPCC, 2007).

Corresponding author: Yasushi Mitsuda

${ }^{* 1}$ Faculty of Agriculture, University of Miyazaki, Miyazaki 889-2192, Japan

E-mail:mitsuda@cc.miyazaki-u.ac.jp
Selecting suitable sites for specific planting species by considering future climate change is a substantially important forest management practice as an adaptation option. Because the cycle of forestry ranges from decades to centuries, the cumulative long-term effect of changing climate during planting to harvesting cannot be neglected. Under changing climatic conditions, stand growth and carbon absorption rate might become lower than those expected with the current climatic condition, indicating a risk of loss of carbon absorption and consequent loss of climate change mitigation effect (e.g. Bonan, 2008). Changing a species planted in a forest to another one often requires the cleanup of the planted trees and re-plantation, which might result in economic loss and increase the risk of soil loss; therefore, changing planting species at the middle of a timber rotation period might not be acceptable. Thus, forest managers need to be cautious in selecting planting species for a site, in other words, specific species should be planted at suitable sites while considering future climate change. This can be considered as one of the most important climate change adaptation option as well as a critical mitigation options.

Assessing the impacts of climate change on forest ecosystems is essential for suggesting adaptation options for forest policy development (e.g. Smit et al., 2014). For selecting suitable sites for a specific species as a climate change adaptation 
option, predicting the effect of climate change on site potential productivity is essential. Previous studies suggested that climate change might affect several aspects of forest dynamics, such as colonization, regeneration, growth, and competition; this might then cause a shift in the suitable habitat for a specific species in the natural forest and change the spatial distribution of plant community (e.g. Bonan, 2008; Spies et al., 2010). Further shifts in suitable sites for plant species in natural forests might affect the potential site productivity of even-aged mono-species-planted forests due to climate change (e.g. Coops and Waring, 2001; Coops et al., 2005; Matsumoto et al., 1992). A site considered good for a planting species might become unsuitable for that species in the future owing to the changing climatic condition; thus, forest managers are required to consider future suitability of a target site for planting species of interest to avoid the risk of economic loss.

Potential site productivity of a specific species is affected by several factors such as temperature, humidity, and soil fertility, and several measures of site productivity have been developed (e.g. Wang and Klinka, 1996). The most widely used measure of site productivity is the site index (e.g. Davis and Johnson, 1987; Hägglund, 1981; Monserud et al., 1990; Takeshita et al., 1960), the other major indicator of potential site productivity is the estimated stand growth determined using a growth prediction model (e.g. Coops et al., 1998; Fox et al., 1985; Sands et al., 2000). We developed a sugi site index prediction model, which allowed explaining the variance in site index varying with high-resolution topography (Mitsuda et al., 2007; Mitsuda and Ito, 2015). Nonetheless, a growth prediction approach developed using a growth model based on climatic condition as explanatory variables might be suitable for representing changes in site productivity caused by climate change, which is the target issue of this study.

Deciding re-planting options after clear-cutting is a current issue of interest in Kyushu District, Japan. Clear-cutting areas have been increasing in this region, because planted forests have matured enough for harvesting, and timber demands have increased. In Kyushu District, as well as in other regions of Japan, planting of even-aged mono-species by using the clear-cutting system is a common forestry practice. The dominant planting species in this region is sugi (Cryptomeria japonica), which occupies approximately 20\% of the land area of Kyushu Island. Forest managers are now facing problems whether they conduct re-planting, because of economic reasons. Local forest officers are also facing the same kind of problem since they need to promote re-planting. The information regarding feature forest productivity might help them reach decisions on these problems.

This study aimed to evaluate the effect of climate change on the potential site productivity of sugi-planted forests in Kyushu Island. We developed maps of site productivity estimated using current and future climatic data, and then compared them to generate a map of sugi site productivity change. Maps of sugi potential site productivity obtained in this study might help forest managers and policy makers to recognize suitable sites for sugi re-plantation as a climate change adaptation option.

\section{MATERIALS AND METHODS}

The study area was the main island of Kyushu, where the area of clear-cutting in planted forests was increasing rapidly. The target tree species was sugi which is the most dominant planting species in Japan as well as in Kyushu District. The 30 -year-average climatic data of a $1-\mathrm{km}$ grid published by the Japan Meteorological Agency was used as the current climatic data. As the future climatic data, simulated climatic values at 2050 were calculated using MIROC-h 3.2, which was developed by K-1 model developers (K-1 model developers, 2004) and interpolated to 1-km resolution by the Agro-Meteorology Division of the National Institute for Agro-Environmental Sciences. The average annual mean temperatures of the study area of current and future climate were $12.5^{\circ} \mathrm{C}$ and $13.4^{\circ} \mathrm{C}$, respectively.

The stand growth prediction model used in this study was a carbon balance-based growth model derived from the 3PG model (Landsberg and Waring, 1997) that had been developed previously (Mitsuda et al., 2011; 2013). This model treats forest stands as four biomass pools, i.e., foliage, branch, stem, and root, and calculates carbon balance at monthly timestep as follows. Photosynthetically active radiation absorbed by foliage (APAR $[\mathrm{MJ} / \mathrm{ha} / \mathrm{month}], \varphi_{p a}$ ) was calculated using Monsi-Saeki's law (Monsi and Saeki, 1953).

$$
\varphi_{p a}=\varphi_{p}\left(1-\exp \left(-K W_{f}\right)\right)
$$

where $K$ is the light-extinction coefficient, $\varphi_{p}$ is photosynthetically active radiation (PAR $[\mathrm{MJ} / \mathrm{ha} / \mathrm{month}]$ ) assumed to be half of the total shortwave incoming radiation, and $W_{f}$ ([ton/ ha]) is foliage biomass.

The potential gross photosynthetic rate per unit foliage weight ( $P A_{G}$ [ton/ton/month]), which is determined by only APAR and is not considered as a photosynthetic rate limiting factor for photoinhibition, was calculated using a light-response curve of canopy photosynthesis represented by a nonrectangular hyperbola (e.g. Hirose and Werger, 1987).

$$
\begin{aligned}
& P A_{G}=\frac{a I+A_{\text {max }}-\sqrt{\left(a I+A_{\text {max }}\right)^{2}-4 a I \theta A_{\text {max }}}}{2 \theta} \\
& I=\frac{\varphi_{p a}}{W_{f}}
\end{aligned}
$$

where $a$ is the initial slope of the light-response curve, $A_{\max }$ is the light-saturated gross photosynthetic rate, $\theta$ is the convexity of the light-response curve, and $I$ is the APAR per unit foliage weight.

There were only two environmental constraints on photosynthetic rate, i.e., are temperature and humidity. The temperature modifier $\left(M_{T}\right)$, which represents constraint of lower 
temperature and ranged from 0 to 1 , was calculated using the following function.

$$
M_{T}=\frac{1}{1+\exp \left(-\beta_{T 1}\left(T-\beta_{T 2}\right)\right)}
$$

where $\beta_{T 1}$ and $\beta_{T 2}$ are the coefficients representing the pattern of response of photosynthetic rate to temperature, and $T$ is the monthly average temperature $\left(\left[{ }^{\circ} \mathrm{C}\right]\right)$.

The humidity modifier $\left(M_{H}\right)$, which represents the constraint of higher air dryness and ranged from 0 to 1 , was calculated using the following function.

$$
M_{H}=\left\{\begin{array}{cc}
\exp \left(-\beta_{H 1}\left(V-\beta_{H 2}\right)\right) & \left(V>\beta_{H 2}\right) \\
1 &
\end{array}\right.
$$

where $\mathrm{MH}$ is the humidity modifier, $\beta_{H 1}$ and $\beta_{H 2}$ are the coefficients representing the pattern of response of photosynthetic rate to humidity, and $V$ is the monthly average of vapor pressure deficit (VPD [kPa]), which represents the degree of air dryness and has a higher value when air humidity is lower.

The actual gross photosynthetic rate $\left(A_{G}\right.$ [ton/ton/ month]) is calculated as modified $P A_{G}$ constrained by temperature and humidity modifier, and then the monthly gross primary production of canopy photosynthesis (GPP [ton/ha/ month]) is calculated as follows.

$$
\begin{aligned}
& A_{G}=P A_{G} \times M_{T} \times M_{H} \\
& \mathrm{GPP}=A_{G} \times W_{f}
\end{aligned}
$$

This model calculates respiration of each biomass pool as follows (e.g. Mori et al., 2010):

$$
\begin{aligned}
& R_{j}=r_{j} \times W_{f} \\
& r_{j}=\beta_{r 1} \exp \left(\beta_{r 2} T\right)
\end{aligned}
$$

where $R_{j}$ ([ton/ha/month]) is respiration, $r_{j}$ ([ton/ton/ month]) is respiration rate per unit biomass, and $W_{j}$ is biomass for each biomass pool $j$ ( $f$ : foliage, $b$ : branch, $s$ : stem, and $r$ : root). $\beta_{r 1}$ and $\beta_{r 2}$ are the coefficients of respiration rate-determining function obtained using temperature $(T)$ as an explanatory variable. $\beta_{r 1 F}$ and $\beta_{r 2 F}$ are used for calculating foliage respiration rate, and $\beta_{r 1 C}$ and $\beta_{r 2 C}$ are used for other biomass pools.

The monthly net primary production (NPP [ton/ha/ month]) was calculated as the surplus of GPP consumed by respiration, and then the monthly biomass growth (BG [ton/ ha/month]) was estimated as the surplus NPP consumed by litterfall and turnover.

$$
\begin{aligned}
& \mathrm{NPP}=\mathrm{GPP}-\sum_{j} R_{j} \\
& \mathrm{BG}=\mathrm{NPP}-\sum_{j} L_{j} \\
& L_{j}=l_{j} \times W_{f}
\end{aligned}
$$

where $L_{j}$ ([ton/ha/month]) is litterfall and turnover, and $l_{j}$ ([ton/ton/month]) is litterfall and turnover rate per unit bio-
Table 1 Parameters of the carbon balance-based stand growth model

\begin{tabular}{llllll}
\hline Parameter & Value & & Parameter & Value \\
\cline { 1 - 2 } \cline { 5 - 6 } Amax & 0.21 & & $\beta_{r 1} F$ & 8.90 \\
$a$ & 0.98 & & $\beta_{r 2} F$ & 2.23 \\
$\theta$ & 2.00 & & $\beta_{r 1} C$ & 1.98 \\
$\beta_{T 1}$ & 0.50 & & $\beta_{r 2} C$ & 1.93 \\
$\beta_{T 2}$ & 0.36 & & $l_{f}$ & 0.22 \\
$\beta_{H 1}$ & 4.81 & & $l_{b}$ & 0.08 \\
$\beta_{H 2}$ & 0.15 & & $l_{f r}$ & 1.00 \\
\cline { 1 - 3 } & 1.00 & & $l_{c r}$ & 0.01 \\
\hline
\end{tabular}

mass for each biomass pool $j$ ( $f$ : foliage, $b$ : branch, fr: fine root, and cr: coarse root).

Thus, biomass growth was estimated as the surplus of canopy photosynthesis production; biomass growth was divided into each biomass pool, and the share of biomass growth was thought to con-tribute to the increase in each biomass pool. All parameters used in this model, which were prepared for sugi, are listed in Table 1. Details of this model have been explained in our previous study (Mitsuda et al., 2011; 2013).

The potential site productivity of sugi-planted forest was estimated using this carbon balance-based stand growth model. This growth model considers the initial biomass of each biomass pool as the initial state of stand and solar radiation, temperature, and humidity as inputs for simulation. Climatic values were obtained from the current and future climate database described above. Because this study aimed to estimate potential site productivity, the stand state could be assumed to be uniform for every site to avoid the effect of initial stand state on growth simulation. The initial biomass of each biomass pool was uniformly set as the value of measurement data of a 15-year-old sugi-planted stand. The spatial unit of this study was 1-km grid, which had the same resolution as that of the climatic data, and the 15-year-old sugi-planted stand was virtually located in each 1 -km grid in Kyushu Island. Several measures of stand growth have been used as indices of site productivity such as mean annual volume increment (e.g. Sands et al., 2000) and NPP (e.g. Coops et al., 1998), averages of 10-year NPP simulated using the growth model by using current and future climate data were regarded as current and future potential site productivity of sugi-planted forest, respectively, in this study.

\section{RESULTS AND DISCUSSION}

The histogram and spatial distribution map for potential site productivity calculated as the average of 10-year NPP derived from growth model simulation by using the current climatic condition are shown in Fig. 1a and Fig. 2a. The average and standard deviation of current potential site productivity for the entire study area were 19.09 and 2.00 [ton/ha/ year].

The estimated current potential site productivity sug- 


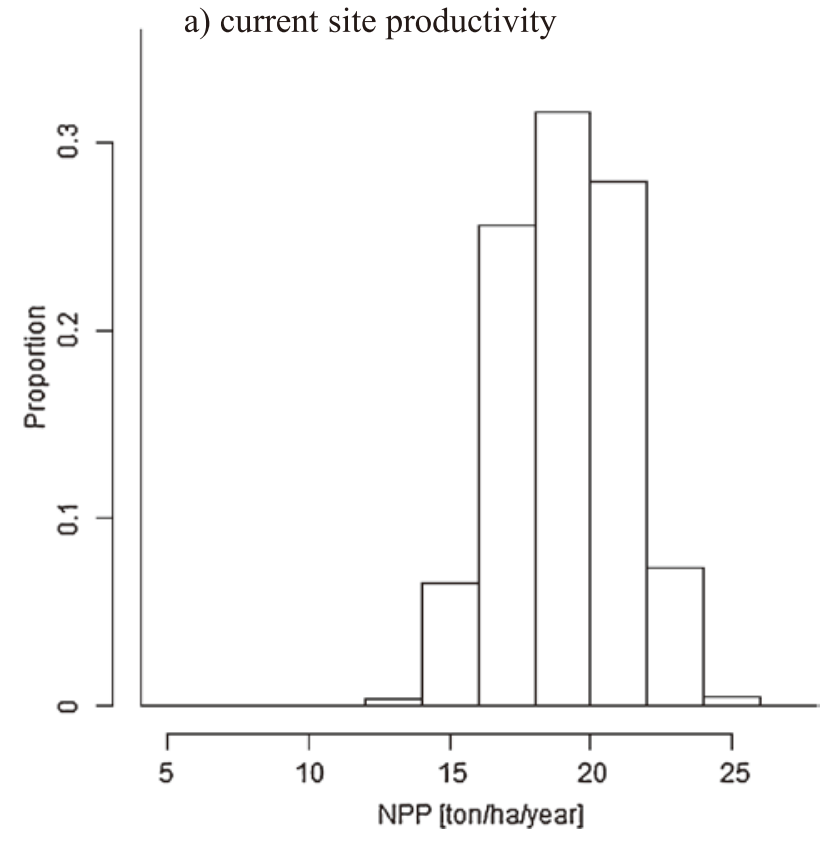

b) future site productivity

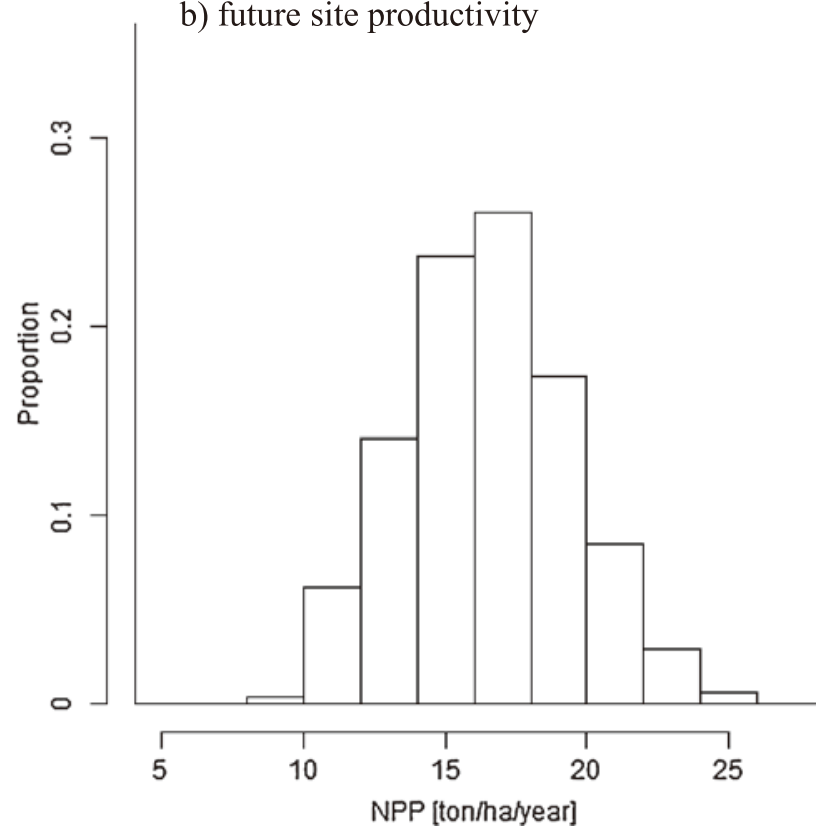

Fig. 1 The histograms of estimated a) current and b) future potential site productivity of sugi-planted forest in Kyushu Island.

gested that Kyushu Island was suitable for sugi-planted forests, although the values might have been over-estimated. Previous studies showed that NPP of sugi-planted stands of various stand age in Kyushu District ranged from 9.7 to 18.8 [ton/ha/year] (Tadaki et al., 1965; 1967). The estimated average of NPP calculated using the current climate data was 19.09 [ton/ha/year], which might be very high as the average NPP of the entire Kyushu Island, although the NPP was calculated when the plantations were younger age class (15to 24-year-old), and sugi-planted forest are known to grow faster than other age class. This study estimated the NPP for the entire land area of Kyushu Island, including lower land city, residential, and agricultural areas, where the climate was warmer than that in mountainous area; this could be one of the reasons for the higher average NPP for the Kyushu Island.

The histogram and spatial distribution map for the future potential site productivity are shown in Fig. 1b and Fig. 2b; and those for the difference between current and future potential site productivity are shown in Fig. 3 and Fig. 4. The average and standard deviation of future potential site productivity and those of their difference for the entire study area were 16.48 and 2.93 [ton/ha/year], and -2.61 and 2.14 [ton/ ha/year], respectively. The difference in the potential site productivity of $87 \%$ of land was negative, and it increased only in high mountain areas.

Site productivity of sugi-planted forest generally decreased in Kyushu Island considering the estimated future condition caused by an increase of temperature. The potential site productivity of sugi-planted forest was estimated as an average of 10-year NPP calculated using the stand growth model; therefore, we assumed that the potential site productivity was affected by solar radiation, temperature, and humidity. In the predicted future climate data, solar radiation was not very different from that of the current climate. The parameter values of humidity modifier function $\left(\beta_{H 1}\right.$ and $\left.\beta_{H 2}\right)$ ensured that the humidity modifier acted as a photosynthetic rate restriction factor under extremely dry condition; thus, the humidity modifier was not a dominant factor for future climatic condition. The temperature modifier did not decrease the stand growth under higher temperature condition because of the form of this function. In fact, NPP was estimated to be higher under future warmer conditions than under the current condition in high mountainous area. The main factor for the decreased NPP was the increase of respiration rate, which was an important determinant factor of NPP (e.g. Valentini et al., 2000) and represented as a function of temperature in this study. Kyushu District is generally warmer than the other regions in Japan, and the effect of temperature modifier on NPP was small. The improvement of carbon balance in cooler season was limited, and the decline of NPP caused by the increase of respiration rate in the hot season was critical.

Matsumoto et al. (1992) showed the high water stress vulnerability of sugi and suggested that water stress could be responsible for the decline of sugi-planted forest in Kanto District, Japan, whereas humidity did not have a large impact because of the parameter values used in the growth model in this study. Hence, the parameter values need to be checked, and the carbon balance-based growth model needs to be re-parameterized. Because of the form of respiration rate-determining function, higher temperature might induce an exponential increase in respiration rate, and this model cannot consider the effect of acclimation (e.g. Atkin and Tjoelker, 2003). This could be the reason for the over-estimation of respiration and the consequent under-estimation of NPP; therefore, some modification of the carbon balance-based growth model used in this study is required for more appropriate pre- 
a) current site productivity

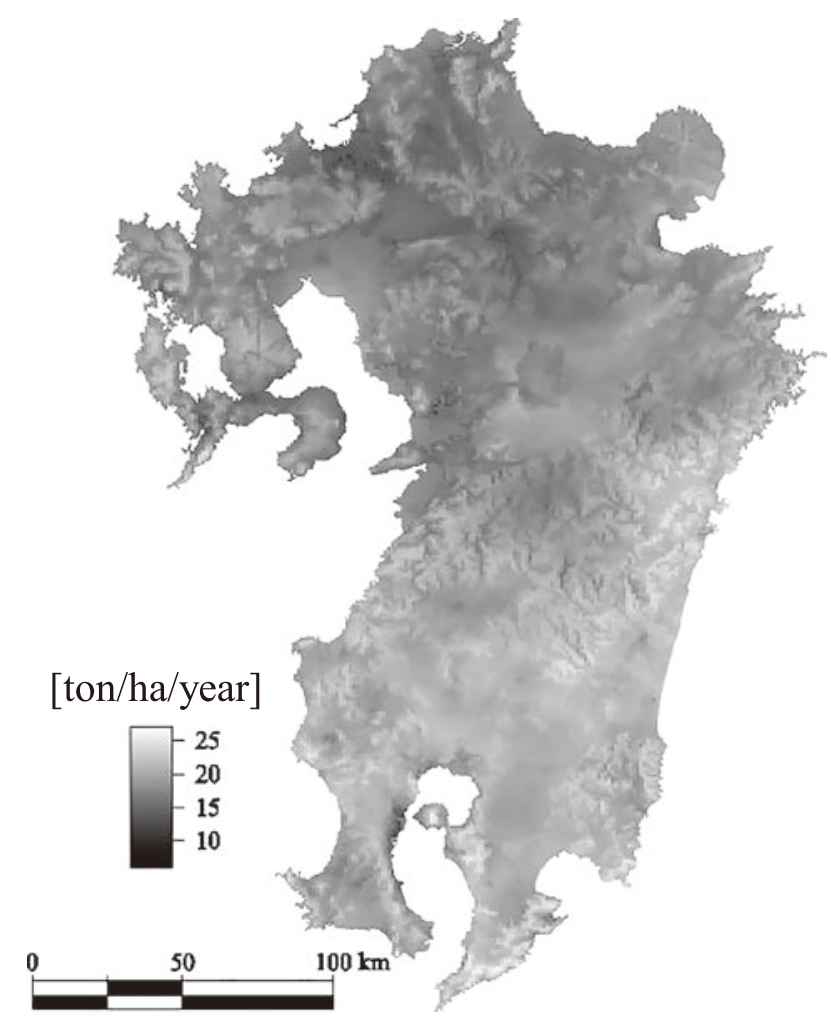

b) future site productivity

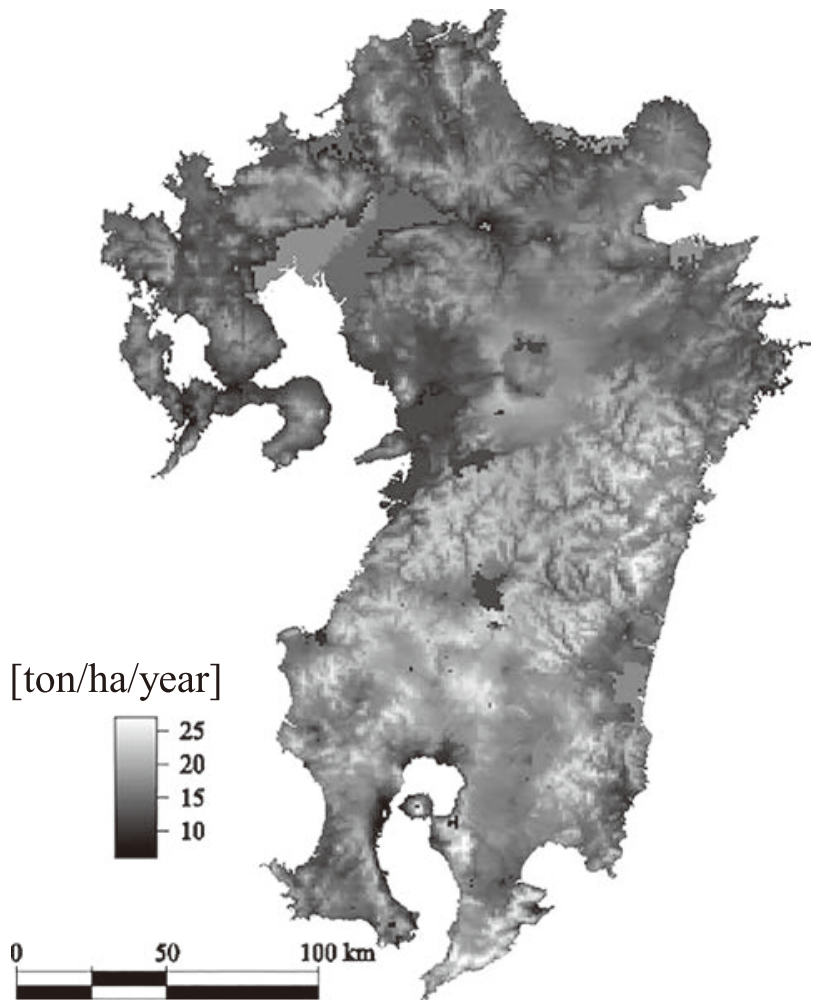

Fig. 2 The spatial distribution maps of estimated a) current and b) future potential site productivity of sugi-planted forest in Kyushu Island.

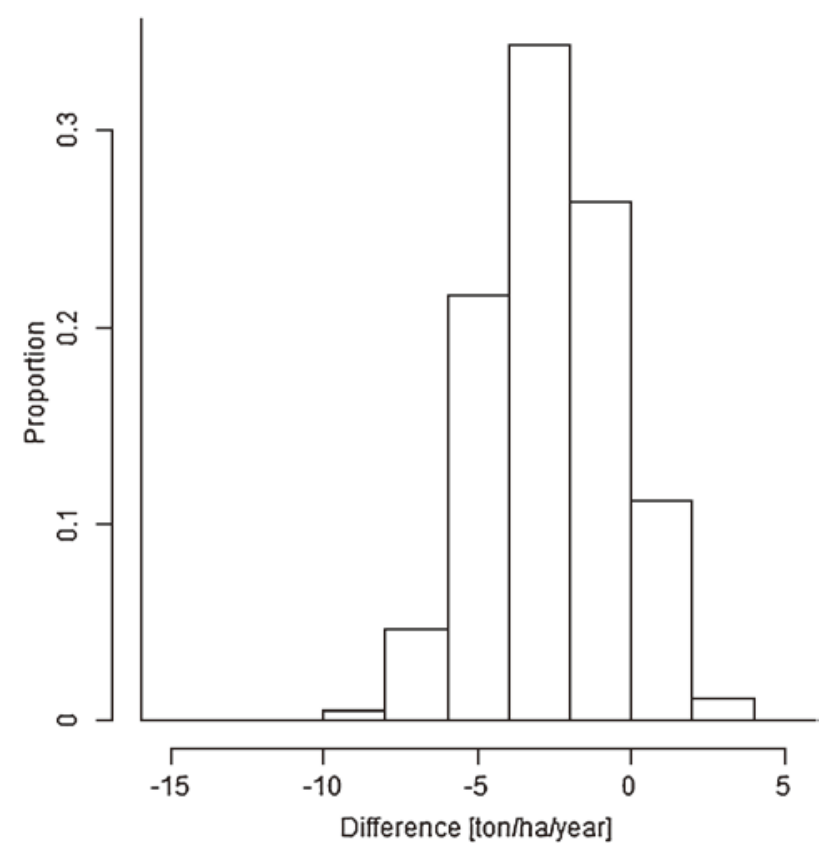

Fig. 3 The histograms of the difference between the estimated current and future potential site productivity of sugiplanted forest in Kyushu Island.

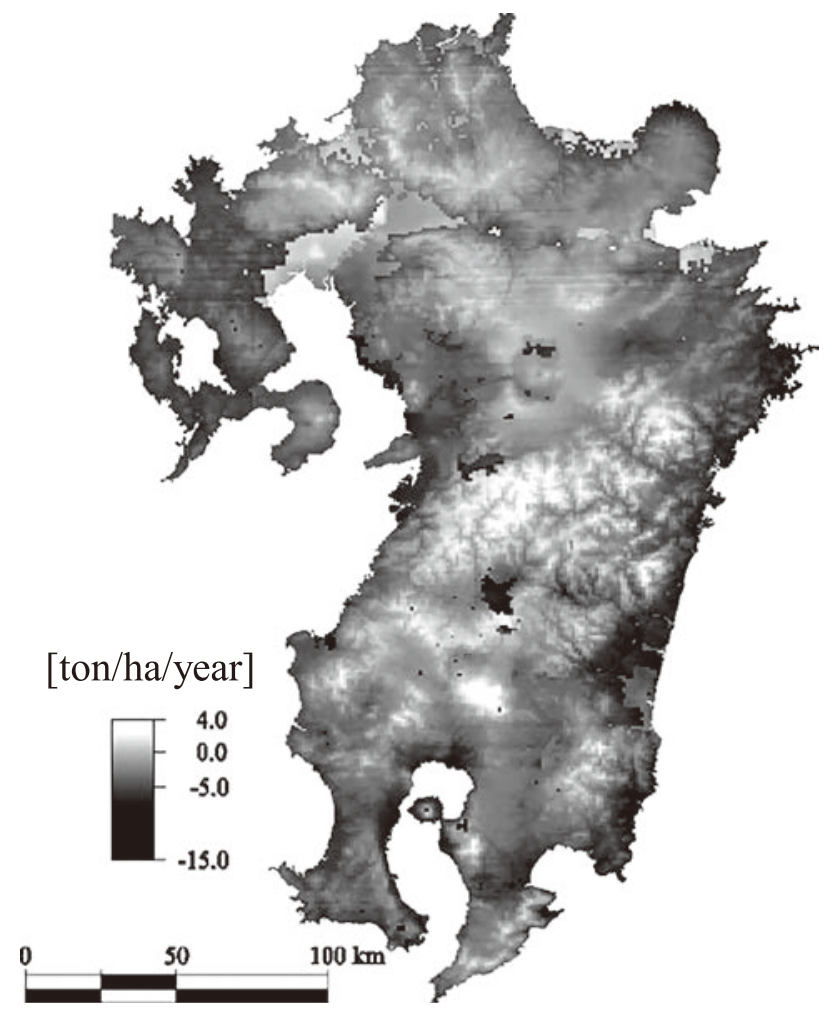

Fig. 4 The spatial distribution maps of the difference between the estimated current and future potential site productivity of sugi planted forest in Kyushu Island. 
dictions of future climate condition.

The results of this study suggested that the potential site productivity of sugi-planted forest would generally decrease under the predicted climate change condition in Kyushu Island. The distribution map of the difference between the estimated current and future potential site productivity might help forest manages and forest policy makers to reach decisions on re-planting of sugi after clear-cutting. As a climate change adaptation option, avoiding re-planting of a specific planting species at sites where site productivity of the species might remarkably decrease in the future is the first step. Following the decision of re-planting, further forest management applications such as replanting by other planting species and restoration of natural forest is needed for future sustainable forest management, and forest managers are required to consider the effects of climate change on not only carbon issue but also several aspects of multiple forest functions such as biodiversity conservation, soil conservation, and timber production. Comprehensive studies regarding the effects of climate change on forest ecosystems are needed to provide climate change adaptation options for forest managers and forest policy makers to achieve sustainable forest management under changing climate condition.

\section{ACKNOWLEDGEMENTS}

This study was supported by JSPS KAKENHI Number 25850112, 25252029, and 15K07483 and Agriculture, Forestry and Fisheries Research Council (Development of technology for impacts, mitigation and adaptation to climate change in the sectors of agriculture, forestry, and fisheries). I would like to thank to the Agro-Meteorology Division of the National Institute for Agro-Environmental Sciences for providing the future climate data.

\section{LITERATURE CITED}

Atkin, O.K. and Tjoelker, M.G. (2003) Thermal acclimation and the dynamic response of plant respiration to temperature. Trends Plant Sci. 8: 343-351

Bonan, G.B. (2008) Forests and climate change: Forcings, feedbacks, and the climate benefits of forests. Science 320: 1444-1449

Canadell, J.G. and Raupach, M.R. (2008) Managing forests for climate change mitigation. Science 320: 1456-1457

Coops, N.C. and Waring, R.H. (2001) Assessing forest growth across southwestern Oregon under a range of current and future global change scenarios using a process model, 3-PG. Glob. Change Biol. 7: 15-29

Coops, N.C., Waring, R.H. and Landsberg, J.J. (1998) Assessing forest productivity in Australia and New Zealand using a physiologically-based model driven with averaged monthly weather data and satellite-derived estimates of canopy photosynthetic capacity. For. Ecol. Manage. 104: 113-127

Coops, N.C., Waring, R.H. and Law, B.E. (2005) Assessing the past and future distribution and productivity of ponderosa pine in the Pacific Northwest using a process model, 3-PG. Ecol. Modell. 183: 107-124

Davis, L.S. and Johnson, K.N. (1987) Forest Management. 3rd ed. McGraw-Hill, New York, 790pp

Fox, III, L., Brockhaus, J.A. and Tosta, N.D. (1985) Classification of timberland productivity in northwestern California using landsat, topography, and ecological data. PE \& RS 51: 1745-1752

Hägglund, B. (1981) Evaluation of forest site productivity. For. Abst. 42: 515-527

Hirose, T. and Werger, M.J.A. (1987) Maximizing daily canopy photosynthesis with respect to the leaf nitrogen allocation pattern in the canopy. Oecologia 72: 520-526

IPCC (2007) Contribution of working group III to the fourth assessment report of the intergovernmental panel on climate change. Cambridge University Press, Cambridge

K-1 model developers (2004) K-1 coupled model (MIROC) description. Center for System Research, University of Tokyo, Tokyo, Japan

Landsberg, J. and Waring, R. (1997) A generalized model of forest productivity using simplified concepts of radiation-use efficiency, carbon balance and partitioning. For. Ecol. Manage. 95: 209-228

Lempriere, T., Kurz, W., Hogg, E., Schmoll, C., Rampley, G., Yemshanov, D., McKenney, D., Gilsenan, R., Beatch, A., Blain, D., Bhatti, J. and Krcmar, E. (2013) Canadian boreal forests and climate change mitigation. Environ. Rev. 21: 293-321

Matsumoto, M., Oka, H., Mitsuda, Y., Hashimoto, S., Kayo, C., Tsunetsugu, Y. and Tonosaki, M. (2016) Potential contributions of forestry and wood use to climate change mitigation in Japan. J. For. Res. 21: 211-222

Matsumoto, Y., Maruyama, Y. and Morikawa, Y. (1992) Some aspects of water relations on large Cryptmeria japonica D. Don trees and climatic changes on the Kanto plains Japan in relation to forest decline. Jpn. J. For. Environ. 34: 2-13 (in Japanese with English summary)

Mitsuda, Y., Hosoda, K. and Iehara, T. (2013) Parameterization of a forest stand growth model using long-term field survey plot data. Proc. Inst. Statist. Math. 61: 307-322 (In Japanese with English summary)

Mitsuda, Y., Hosoda, K., Iehara, T. and Matsumoto, M. (2011) Preliminary analysis on the use of a process-based forest growth model of Cryptomeria japonica planted forest to represent the effects of canopy structure change. FORMATH 10: 169-193

Mitsuda, Y. and Ito, S. (2015) Modifying the site index model of sugi planted forests in Miyazaki Prefecture considering the effects of DEM quality and scale of digital terrain analysis. J. For. Plann. 20: 45-51

Mitsuda, Y., Ito, S. and Sakamoto, S. (2007) Predicting the site 
index of sugi plantations from GIS-derived environmental factors in Miyazaki Prefecture. J. For. Res. 12: 177-186

Monserud, R.A., Moody, U. and Breuer, D.W. (1990) A soilsite study for inland Douglas-fir. Can. J. For. Res. 20: 686695

Monsi, M. and Saeki, T. (1953) Über den lichtfaktor in den pflanzengesellschaften und seine bedeutung für die stoffproduktion. Jpn. J. Bot. 14: 22-52

Mori, S., Yamaji, K., Ishida, A., Prokushkin, S.G., Masyagina, O.V., Hagihara, A., Hoque, A.R., Suwa, R., Osawa, A., Nishizono, T., Ueda, T., Kinjo, M., Miyagi, T., Kajimoto, T., Koike, T., Matsuura, Y., Toma, T., Zyryanova, O.A., Abaimov, A.P., Awaya, Y., Araki, M.G., Kawasaki, T., Chiba, Y. and Umari, M. (2010) Mixed-power scaling of wholeplant respiration from seedlings to giant trees. PNAS 107: 1447-1451

Sands, P.J., Battaglia, M. and Mummery, D. (2000) Application of process-based models to forest management: experience with PROMOD, a simple plantation productivity model. Tree Physiol. 20: 383-392

Smit, B., Burton, I., Klein, R.J.T. and Wandel, J. (2014) An anatomy of adaptation to climate change and variability. Climatic Change 45: 223-251

Spies, T.A., Giesen, T.W., Swanson, F.J., Franklin, J.F., Lach, D. and Johnson, K.N. (2010) Climate change adaptation strategies for federal forests of the Pacific Northwest, USA: ecological, policy, and socio-economic perspectives. Landscape Ecol. 25: 1185-1199

Spittlehouse, D.L. and Stewart, R.B. (2004) Adaptation to cli- mate change in forest management. J. Ecosystems Manage. 4: $1-11$

Tadaki, T., Ogata, N. and Nagatomo, Y. (1965) The dry matter productivity in several stands of Cryptomeria japonica in Kyushu. Bull. Gov. For. Exp. Stn. 173: 45-66

Tadaki, T., Ogata, N. and Nagatomo, Y. (1967) Studies on production structure of firest. XI. Primary productivities of 28-year-old plantation of Cryptomeria of cuttings and seedlings origin. Bull. Gov. For. Exp. Stn. 199: 47-65

Takeshita, K., Nakanjima, Y., Nagahama, M. and Higuchi, S. (1960) Edaphological studies on micro-topography and forest soil and their relationship to the growth of sugi Cryptmeria races (I). Bull. Fukuoka-pref. For. Exp. Stn. 12: 1-162 (in Japanese with English summary)

Valentini, R., Matteucci, G., Dolman, A.J., Schulze, E.-D., Rebmann, C., Moors, E.J., Granier, A., Gross, P., Jensen, N.O., Pilegaard, K., Lindroth, A., Grelle, A., Bernhofer, C., Grunwald, T., Aubinet, M., Ceulemans, R., Kowalski, A.S., Vesala, T., Rannik, U., Berbigier, P., Loustau, D., Gudmundsson, J., Thorgeirsson, H., Ibrom, A., Morgenstern, K., Clement, R., Moncrieff, J., Montagnani, L., Minerbi, S. and Jarvis, P.G. (2000) Respiration as the main determinant of carbon balance in European forests. Nature 404: 861-865

Wang, G.G. and Klinka, K. (1996) Use of synoptic variables in predicting white spruce site index. For. Ecol. Manage. 80: 95-105

(Received 17 November 2016)

(Accepted 26 May 2017) 